\title{
ERRATUM
}

\section{Erratum to: Diffraction Lloyd mirror interferometer}

\author{
Raj Kumar
}

Published online: 28 April 2013

(C) Optical Society of India 2013

Erratum to: J Opt 39 (2): 90-101

DOI 10.1007/s12596-010-0025-6

The Figure 1 appeared in the original paper was incomplete. The correct figure is shown below.

The online version of the original article can be found at http:// dx.doi.org/10.1007/s12596-010-0025-6.

\section{R. Kumar $(\bowtie)$}

Central Scientific Instruments Organisation,

Chandigarh 160030, India

e-mail:raj_csio@yahoo.com

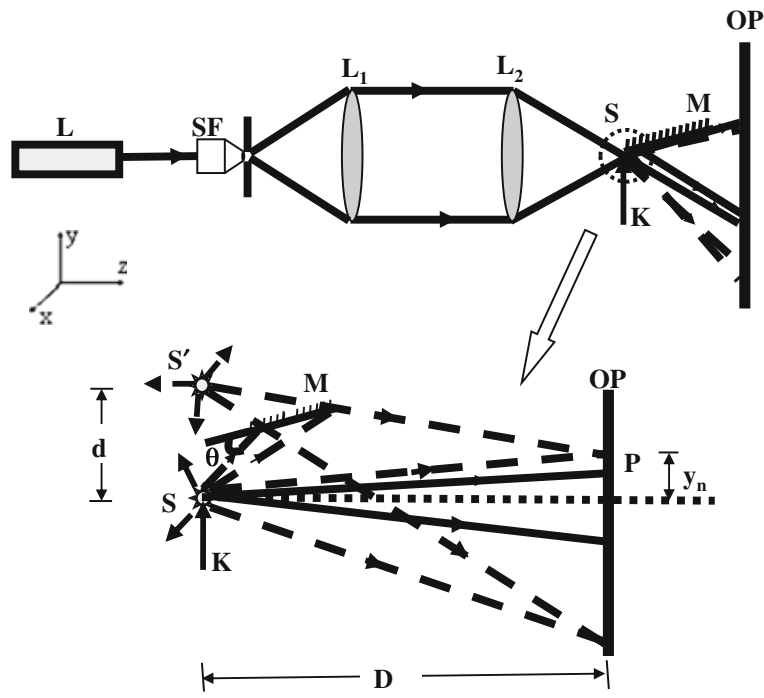

Fig. 1 Schematic representation of diffraction Lloyd's mirror interferometer: $\mathrm{K}$ is knife-edge, $\mathrm{M}$ is Lloyd's mirror, is the angular tilt of the mirror, $h$ is surface displacement parallel to itself and solid line represents the geometrical wave while dotted line represents the boundary diffraction wave 